\title{
PEACE AMONG THE FACTIONS: COOLING TEMPERS IN THE EXTRATERRESTRIAL LIFE DEBATE
}

\author{
D. Brin \\ Heritage Research, Los Angeles, CA 90007 USA
}

\begin{abstract}
$\underline{\text { Summary }}$
Critics of SETI argue that its assumptions and propositions are intrinsically unfalsifiable and therefore unscientific. While this overly-narrow definition of science can easily be refuted, those of us hoping for progress in exobiology are under some obligation to admit that we actually have very little idea what we are talking about. Personal identification with a particular model or theory (always a danger in science) is especially detrimental in this field.

While exobiology comes nominally under the domain of astronomy, the Earth itself remains its central source of both fact and metaphor. The planet's distribution of biomass appears to fit neither the "oasis in a desert" model, nor that of "universal fecundity." Here it is suggested that we may derive patterns of ecological scaling by observing our homeworld. These patterns may offer insight into possible distributions on a galactic scale.

Conjectures about detectable sentient civilizations must be distinguished from those concerning exobiology in general. While the SETI proposition remains healthy it has been forced to mature under heavy criticism during the 1970 s and 1980 s, and now must deal with severe upper-limit constraints. At best, the universe is "sparse" in detectable ETI civilizations. A categorization of those explanations proposed so far shows no reason to believe anyone has yet found "the" answer.
\end{abstract}

